\title{
Erratum to: Approximation model to estimate joint market share in off-hour deliveries
}

\author{
José Holguín-Veras
}

Published online: 3 March 2012

(c) Springer-Verlag 2012

Erratum to: Logist. Res.

DOI 10.1007/s12159-012-0065-1

In the original publication, the title of this article was incorrectly published.

The correct version is given here:

Approximation model to estimate joint market share in off-hour deliveries.

The online version of the original article can be found under doi: 10.1007/s12159-012-0065-1.

J. Holguín-Veras ( $\square)$

Department of Civil and Environmental Engineering,

Rensselaer Polytechnic Institute, JEC 4030,

110 8th Street, Troy, NY 12180, USA

e-mail: jhv@rpi.edu 